\title{
Oral mucocele: review of the literature
}

\author{
J Ata-Ali ${ }^{1}, C$ Carrillo ${ }^{2}, C$ Bonet $^{2}, J_{\text {Balaguer }}^{3}, M_{\text {Peñarrocha }}{ }^{3}$, M Peñarrocha $^{4}$
}

\author{
${ }^{1}$ Master of Oral Medicine and Surgery. Resident of the Master of Oral Surgery and Implantology. Valencia University Medical \\ and Dental School. \\ ${ }^{2}$ Master of Oral Surgery and Implantology. Valencia University Medical and Dental School. \\ ${ }^{3}$ Associate Professor of Oral Surgery. Master of Oral Surgery and Implantology. Valencia University Medical and Dental School. \\ ${ }^{4}$ Professor of Oral Surgery. Director of the Master of Oral Surgery and Implantology. Valencia University Medical and Dental \\ School (Spain).
}

\section{Correspondence:}

Dra. María Peñarrocha Diago

Cirugía Bucal. Clínicas Odontológicas.

Gascó Oliag 1

46021-Valencia. Spain

E-mail: maria.penarrocha@uv.es

\begin{abstract}
Mucocele is a common lesion of the oral mucosa that results from an alteration of minor salivary glands due to a mucous accumulation. Mucocele involves mucin accumulation causing limited swelling. Two histological types exist - extravasation and retention. Mucoceles can appear at any site of the oral mucosa where minor salivary glands are present. Diagnosis is principally clinical; therefore, the anamnesis should be carried out correctly, looking for previous trauma. The most common location of the extravasation mucocele is the lower lip, while retention mucoceles can be found at any other site. Mucoceles can affect the general population, but most commonly young patients (20-30 years old). Clinically they consist of a soft, bluish and transparent cystic swelling which normally resolves spontaneously. Treatment frequently involves surgical removal. Never-theless micro marsupialization, cryosurgery, steroid injections and $\mathrm{CO} 2$ laser are also described.

Mucocele is a common lesion and affects the general population. For this reason we felt it would be interesting review the clinical characteristics of mucoceles, and their treatment and evolution in order to aid decision-making in daily clinical practice.
\end{abstract}

Key words: Mucocele, mucocele treatment, Minor salivary glands. 


\section{Introduction}

Mucocele is a common lesion of the oral mucosa that results from an alteration of minor salivary glands due to a mucous accumulation. Mucocele involves mucin accumulation causing limited swelling (1). Two types of mucocele can appear - extravasation and retention. Extravasation mucocele results from a broken salivary glands duct and the consequent spillage into the soft tissues around this gland. Retention mucocele appears due to a decrease or absence of glandular secretion produced by blockage of the salivary gland ducts (2).

When located on the floor of the mouth these lesions are called ranulas because the inflammation resembles the cheeks of a frog (3).

Mucocele is a common lesion and affects the general population. For this reason we felt it would be interesting review the clinical characteristics of mucoceles, and their treatment and evolution in order to aid decisionmaking in daily clinical practice.

\section{Etiopathogeny}

Yamasoba et al. (4) highlight two crucial etiological factors in mucoceles: traumatism and obstruction of salivary gland ducts.

Mucus is produced exclusively by the minor salivary glands and is also the most important substance secreted by the major sublingual salivary glands. Mucoceles can appear by an extravasation or a retention mechanism. Extravasation mucoceles are caused by a leaking of fluid from surrounding tissue ducts or acini. This type of mucocele is commonly found on the minor salivary glands. Physical trauma can cause a leakage of salivary secretion into surrounding submucosal tissue. Inflammation becomes obvious due to stagnant mucous resulting from extravasation (3).

A study by Bagán et al. (1), considering 25 mucoceles suffered in the general population, showed that $5 \%$ were retention mucoceles whereas the other $95 \%$ were extravasation. They proposed that extravasation mucoceles undergo three evolutionary phases. In the first phase, mucous spills diffusely from the excretory duct into conjunctive tissues where some leucocytes and histiocytes are found. Granulomas appear during the resorption phase due to histocytes, macrophages and giant multinucleated cells associated with a foreign body reaction. In the final phase connective cells form a pseudocapsule without epithelium around the mucosa.

Retention mucoceles are formed by dilation of the duct secondary to its obstruction or caused by a sialolith or dense mucosa. The majority of retention cysts develop in the ducts of the major salivary glands (3).

\section{Clinical Characteristics}

The incidence of mucoceles is generally high, 2.5 lesions per 1000 patients, frequently in the second decade of life (5-7) and rarely among children under one of year of age. According to many studies there is no difference between genders $(1,4,5,8,9)$.

There is no clinical difference between extravasation and retention mucoceles. Mucoceles present a bluish, soft and transparent cystic swelling which frequently resolves spontaneously. The blue colour is caused by vascular congestion, and tissular cyanosis of the tissue above and the accumulation of fluid below. Coloration can also vary depending on the size of the lesion, proximity to the surface and upper tissue elasticity $(3,6,10)$. Lesion duration is not constant, from a few days to 3 years (4). Bagán et al. provide a study of 25 patients suffering from mucoceles. $48 \%$ of the patients became aware of their lesion on seeing it although there were no symptoms. In the case of another $48 \%$, lesions were found by a specialist by chance. Only 4\% patients had some unspecified feeling of discomfort but no real pain (1).

Mucoceles of the minor salivary glands are rarely larger than $1.5 \mathrm{~cm}$ in diameter and are always superficial. Mucoceles found in deeper areas are usually larger. $\mathrm{Mu}-$ coceles can cause a convex swelling depending on the size and location, as well as difficulties in speaking or chewing (3).

Mucoceles can appear at any site of the oral mucosa containing salivary glands (11). The two types of mucoceles are more commonly found at different sites. Extravasation mucoceles appear frequently on the lower lip whereas retention mucoceles appear at any other location of the oral cavity. The lower lip is the most frequent site for a mucocele as it is the most probable place for a trauma, especially at premolar level. A study of 312 patients showed 230 lesions on the lower lip (73.7\%), with the tongue as the second most common location (15.4\%) (9). These locations are followed by the buccal mucosa and palate; and are rarely found in the retromolar region and posterior dorsal area of the tongue (12). Occasionally mucoceles can involve the glands of Blandin-Nuhn (3). These glands are located on the muscle of the ventral side of the tongue; the histological diagnosis is always extravasation type, and normally affecting young patients $(3,5,11)$.

\section{Diagnosis}

Diagnosis is principally clinical; therefore, the anamnesis should be carried out correctly, looking for previous trauma. The appearance of mucoceles is pathognomonic $(6,10)$ and the following data are crucial: lesion location, history of trauma, rapid appearance, variations in size, bluish colour and the consistency (11).

Palpation can be helpful for a correct differential diagnosis. Lipomas and tumors of minor salivary glands present no fluctuation while cysts, mucoceles, abscess and hemangiomas do (5). Mucoceles are mobile lesions with soft and elastic consistency depending on how much tis- 
sue is present over the lesion (6).

Despite this fluctuation, a drained mucocele would not fluctuate and a chronic mucocele with a developed fibrosis would have less fluctuation.

A simple technique known as fine needle aspiration biopsy (FNAB) is very helpful, especially when differential diagnosis of angiomatous lesions is involved. Abundant mucosa without epithelial components is found within mucoceles as well as many inflammatory cells, especially histiocytes (13).

A histopathologic study is crucial to confirm the diagnosis and to ensure that glandular tissue is completely removed. Two types of mucoceles exist: retention mucoceles and extravasation mucoceles.

In the case of retention mucoceles a cyst cavity can be found, this is generally well defined with an epithelial wall covered with a row of cuboidal or flat cells produced from the excretory duct of the salivary glands (3). Compared to extravasation mucoceles, retention mucoceles show no inflammatory reaction and are true cysts with an epithelial covering (5).

Extravasation mucoceles are pseudocysts without defined walls. The extravasated mucous is surrounded by a layer of inflammatory cells and then by a reactive granulation tissue made up of fibroblasts caused by an immune reaction. Even though there is no epithelial covering around the mucosa, this is well encapsulated by the granulation tissue $(2,3,5)$.

\section{Treatment}

Conventional treatment is commonly surgical extirpation of the surrounding mucosa and glandular tissue down to the muscle layer. With a simple incision of the mucocele the content would drain out but the lesion would reappear as soon as the wound heals (8). There is no need for treatment if superficial extravasation mucoceles resolve spontaneously.

Small mucoceles can be removed completely with the marginal glandular tissue before suture. In the case of larger mucoceles, marsupialization would avoid damage to vital structures. Clinically there is no difference between both types of mucocele, and are therefore treated in the same manner. Nevertheless when an obstruction of retention mucoceles is detected treatment involves the removing the top of the cyst and introducing a lacrimal catheter into the duct to dilate it (3).

A study of 14 pediatric patients (14) describes micro marsupialization techniques with $85 \%$ success. The aim of this technique is to drain the mucus and reduce the size of the lesion. This technique (after disinfection and anaesthesia) consists of passing thick silk thread through the lesion at its largest diameter and then making a surgical knot. The suture is removed after 7-10 days, enough time for the mucocele to disappear. This technique has the advantage of being simple, relatively painless and with minimum trauma.

Some studies have reported using cryosurgery in treating mucoceles with encouraging results $(15,16)$. In one study, 36 mucoceles were removed using cryosurgery and only 2 lesions reappeared (5.6\%) (17). Some authors have also suggested using intralesional steroid injections (18).

$\mathrm{CO} 2$ laser has a high water absorption rate and is well absorbed by all soft tissues with high water content. In addition its effects on adjacent tissues are minimal. These properties make $\mathrm{CO} 2$ laser the perfect surgical treatment for oral soft tissues (19). The cut is precise and does not affect the muscle layer, causes minimal haemorrhage and almost no acute inflammatory reaction. The operation time is short (3-5 minutes) making it a convenient treatment for children and patients who cannot withstand long treatment $(8,20)$.

Huang et al. (8) in a study of 82 patients suffering from mucoceles on the lower lip treated with $\mathrm{CO} 2$ laser observed that 2 lesions reappeared afterwards and one patient suffered temporary paraesthesia. In another study of 68 patients, 30 were treated with $\mathrm{CO} 2$ laser, only one lesion reappeared and there were no postoperative complications. In contrast, due to the more aggressive process, in the 38 cases removed by scalpel there were 9 postoperative complications - a temporary anaesthesia in a $2.4 \mathrm{~cm}$ diameter mucocele located close to the mental nerve, 3 cases of postoperative haemorrhage and 5 patients with fibrous scar tissue after normal healing (7).

The key point in avoiding recurrence is to eliminate the adjacent surrounding glandular acini and removing the lesion down to the muscle layer $(8,20)$. Special care should be taken to avoid injury to the adjacent glands and ducts while placing sutures as this is also a cause for reappearance (3).

Regarding overall recurrence rates, in one study, $70 \mathrm{mu}-$ coceles were surgically removed from the lower lip, and 2 lesions reappeared (2.8\%) (4).

\section{References}

1. Bagán Sebastián JV, Silvestre Donat FJ, Peñarrocha Diago M, Milián Masanet MA. Clinico-pathological study of oral mucoceles. Av Odontoestomatol. 1990;6:389-91, 394-5.

2. Boneu-Bonet F, Vidal-Homs E, Maizcurrana-Tornil A, GonzálezLagunas J.Submaxillary gland mucocele: presentation of a case. Med Oral Patol Oral Cir Bucal. 2005;10:180-4.

3. Baurmash HD. Mucoceles and ranulas. J Oral Maxillofac Surg. 2003;61:369-78.

4. Yamasoba T, Tayama N, Syoji M, Fukuta M. Clinicostatistical study of lower lip mucoceles. Head Neck. 1990;12:316-20.

5. Guimarães MS, Hebling J, Filho VA, Santos LL, Vita TM, Costa CA.Extravasation mucocele involving the ventral surface of the tongue (glands of Blandin-Nuhn). Int J Paediatr Dent. 2006;16:435-9.29. 6. Bentley JM, Barankin B, Guenther LC. A review of common pediatric lip lesions: herpes simplex/recurrent herpes labialis, impetigo, mucoceles, and hemangiomas. Clin Pediatr (Phila). 2003;42:475-82.

7. Yagüe-García J, España-Tost AJ, Berini-Aytés L, Gay-Escoda C. Treatment of oral mucocele-scalpel versus CO2 laser. Med Oral Patol Oral Cir Bucal. 2009;14:e469-74. 
8. Huang IY, Chen CM, Kao YH, Worthington P. Treatment of mucocele of the lower lip with carbon dioxide laser. J Oral Maxillofac Surg. 2007;65:855-8.

9 . de Camargo Moraes P, Bönecker M, Furuse C, Thomaz LA, Teixeira RG, de Araújo VC. Mucocele of the gland of Blandin-Nuhn: histological and clinical findings. Clin Oral Investig. 2009 ;13:351-3.

10. Tran TA, Parlette HL 3rd. Surgical pearl: removal of a large labial mucocele. J Am Acad Dermatol. 1999;40:760-2.

11. Andiran N, Sarikayalar F, Unal OF, Baydar DE, Ozaydin E. Mucocele of the anterior lingual salivary glands: from extravasation to an alarming mass with a benign course. Int J Pediatr Otorhinolaryngol. 2001;61:143-7.

12. Zancopé E, Pereira AC, Ribeiro-Rotta RF, Mendonça EF, Batista AC. Mucocele in posterior dorsal surface of tongue: an extremely rare location. J Oral Maxillofac Surg. 2009;67:1307-10.

13. Layfield LJ, Gopez EV. Cystic lesions of the salivary glands: cytologic features in fine-needle aspiration biopsies. Diagn Cytopathol. 2002;27:197-204.

14. Delbem AC, Cunha RF, Vieira AE, Ribeiro LL. Treatment of mucus retention phenomena in children by the micro-marsupialization technique: case reports. Pediatr Dent. 2000;22:155-8.

15. Marcushamer M, King DL, Ruano NS. Cryosurgery in the management of mucoceles in children. Pediatr Dent. 1997;19:292-3.

16. Gill D. Two simple treatments for lower lip mucocoeles. Australas J Dermatol. 1996;37:220. Erratum in: Australas J Dermatol 1997:38:104

17. Yeh CJ.Simple cryosurgical treatment for oral lesions. Int J Oral Maxillofac Surg. 2000;29:212-6.

18. Luiz AC, Hiraki KR, Lemos CA Jr, Hirota SK, Migliari DA. Treatment of painful and recurrent oral mucoceles with a high-potency topical a corticosteroid: a case report. J Oral Maxillofac Surg. 2008;66:1737-9.

19. Pick RM, Colvard MD. Current status of lasers in soft tissue dental surgery. J Periodontol. 1993;64:589-602.

20. Kopp WK, St-Hilaire H. Mucosal preservation in the treatment of mucocele with CO2 laser. J Oral Maxillofac Surg. 2004;62:1559-61. 